\title{
The pattern of gynecological malignancies in Al-Madinah Al-Munawarah region, Saudi Arabia
}

\author{
An overview of 6 years
}

Nawal H. Almohammadi, MD, SB-AntPath.

\begin{abstract}
الأهداف : تحليل أنماط المريضات المصابات بسرطان الجهازي التناسلي للإناث

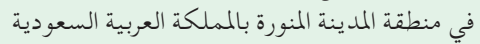

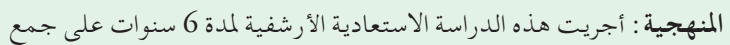

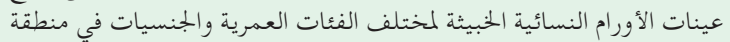

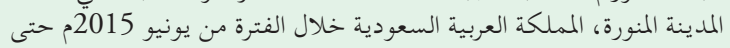

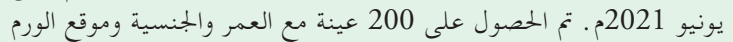

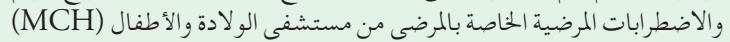

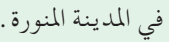

النتائج: كان سرطان بطانة الرحم هو الورم الخبيث الأكثر شيوعًا (69.0\%)

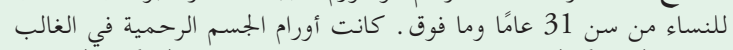

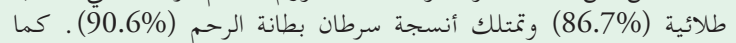

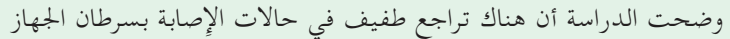

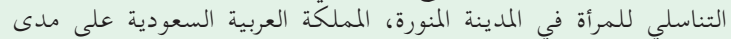
السنوات 6 الماضية.

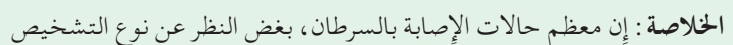

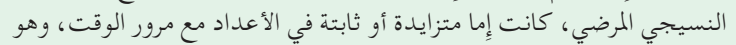

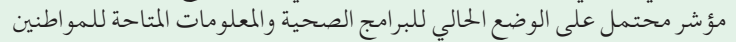

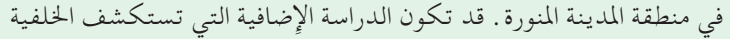

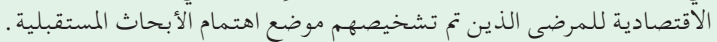

Objectives: To describe the frequency and spectrum of different types of gynecological malignancies (malignant tumors of the female genital tract) and to characterize the pattern of gynecological neoplasms in different age groups in Al-Madinah Al-Munawarah, Saudi Arabia.

Methods: This 6-year retrospective-design research was carried out on different age groups in Al-Madinah Al-Munawarah region, from June 2015 until June 2021. The patients' information of all 200 specimens, including age, nationality, tumor site, and pathological disorders was obtained from the Maternity and Children Hospital, Al-Madinah Al-Munawarah.

Results: Endometrial cancer was the most common malignancy for women of 31 years and above $(69.0 \%)$. Tumors of the uterine corpus were mostly epithelial
(86.7\%) and possessed an endometrioid carcinoma histology (90.6\%). There was only a small decline in gynecological cancer incidences in Al-Madinah Al-Munawarah over the past 6 years.

Conclusion: Most of the cancer incidences, regardless of the pathological diagnosis, either increased or remained unchanged over time, is a possible indication of the current state of health programs and information available to the citizens in Al-Madinah Al-Munawarah. Further studies exploring the economic background of diagnosed patients may be of interest to future research.

Keywords: gynecological neoplasm, female genital, tumors

Saudi Med J 2022; Vol. 43 (3): 283-290

doi: 10.15537/smj.2022.43.3.20210888

From the Department of Pathology, College of Medicine, Taibah University, Al-Madinah Al-Munawarah, Kingdom of Saudi Arabia.

Received 4th November 2021. Accepted 24th January 2022.

Address correspondence and reprint request to: Dr. Nawal $H$. Almohammadi, Assistant Professor, Department of Pathology, College of Medicine, Taibah University, Al-Madinah Al-Munawarah, Kingdom of Saudi Arabia.E-mail: nhmohammadi@taibahu.edu.sa ORCID ID: https://orcid.org/0000-0002-0784-4826

Cancer remains one of the major health concerns globally, having an estimated new cancer cases reaching 19.3 million (18.1 million excluding nonmelanoma skin cancer) and almost 10.0 million cancer deaths (9.9 million excluding nonmelanoma skin cancer) occurred in 2020 worldwide. ${ }^{1}$ Behaviors and habits that are linked to higher cancer rates greatly increase the burden of cancer, especially in economically developing countries. Males are often the most diagnosed with lung cancer, while the cancer type prominent in females is breast cancer. ${ }^{2}$ Aside from breast 
cancer, gynecological cancer is also a point of concern of women's public health. According to the International Agency for Research on Cancer (IARC), gynecological cancers are accounted for the rate of $19 \%$ out of the 5.1 million estimated new cancer cases worldwide in the year 2002. ${ }^{3}$ In Saudi Arabia, the IARC reported more than 13000 cases of cancer among Saudi women in 2020. Corpus uteri cancer tops the list of gynecological types of cancer, accounting for $7.5 \%$ of the overall cases among Saudi women. ${ }^{4}$ In an effort to diminish the number of new gynecological cancer diagnoses and advance the treatment of malignancy, it is imperative to gain a better understanding of its incidence and prevalence across all ages and nationalities. Studies focusing on gynecological malignancy are rare and present only small population sizes or brief study durations. ${ }^{5}$ Minimal information on gynecological malignancies and neoplasms is available in Saudi Arabia particularly in Al-Madinah Al-Munawarah. As such, this research aims to carry out a 6-year retrospective study describing the frequency and spectrum of different types of gynecological malignancies (malignant tumors of the female genital tract) and characterizing the pattern of gynecological neoplasms in different age groups in the region.

Methods. This is a 6-year retrospective histopathological evaluation of the female genital tract malignancy pattern in Al-Madinah Al-Munawarah. The Pathology Department at the Maternity and Children Hospital $(\mathrm{MCH})$ is a public referral laboratory that provides gynecological diagnostic pathology services in its area. All diagnoses of female genital tract malignancies from June 2015 until June 2021 were collected and histologically confirmed by 2 consultant pathologists. The inclusion criteria was of any cancer diagnosis in all female patients of all age groups. Female patients with more than one sample of the same lesion were counted once. The exclusion criteria was all precursor lesions/in situ malignancy and inflammatory condition.

The samples were obtained from biopsy specimens of inpatients and referrals from histopathology labs from government and private health centers. The specimens were fixed in $10 \%$ formalin embedded in paraffin wax. Sections were stained with routine hematoxylin and eosin. Demographic data, which included age, nationality, tumor site, and pathological diagnosis were extracted from the laboratory registry, request forms,

Disclosure. Author has no conflict of interests, and the work was not supported or funded by any drug company. and patients' electronic records. Cases that did not include any of the above variables were excluded.

Only $47.7 \%$ out of 100,000 have cancer related to gynecological malignancies or $0.0477 \%$ or $>1 \% .^{6}$ Thus, following the sampling formula with $5 \%$ margin of error, $95 \%$ confidence interval (CI), and an estimated population of 10,000,000 Saudi women, 200 samples were substantial enough and more than ideal with an estimated margin of error of $1.38 \%$.

Statistical analysis. Data was analyzed using Statistical Package for the Social Sciences for Windows, version 23 (IBM Corp., Armonk, NY, USA). Simple descriptive statistics was used to define the characteristics of the study variables through a form of counts and percentages for the categorical and nominal variables while continuous variables were presented by mean and standard deviations (SD). To compare 2 group means and more than 2 groups, one-way ANOVA was used. This test was carried out with the assumption of normal distribution. Otherwise, Game's Howell for multiple groups was utilized. Moreover, Chi-square test was employed to establish a relationship between categorical variables. A conventional $p$-value of $<0.05$ was the criteria to reject the null hypothesis.

Approval from the Institutional Review Board (H-03-M-084) at Ministry of Health, Al-Madinah AlMunawarah, was obtained. This study also followed the Helsinki declaration on human subjects.

Results. A total of 200 specimens diagnosed with female genital tract malignancy were found to satisfy the necessary details on demographic information. The specimens were obtained from women with a mean age of $54.40 \pm 16.1$ years. The majority of the specimens were obtained in the years 2016 and 2017 (17.5\%) and were from Saudi Arabians (84\%). Genital tract malignancies were found mostly in the uterus (69\%), cervix (13.5\%), and ovaries (13.5\%; Table 1$)$.

The International Federation of Gynecology and Obstetrics (FIGO) grading system was used to grade uterine carcinomas. This grading system applies only to endometrioid and mucinous carcinomas. It excludes high-grade cases such as serous, clear cell, transitional, and neuroendocrine carcinomas; undifferentiated/ dedifferentiated carcinomas; and carcinosarcomas. The FIGO grading was then utilized to describe how the cancer cells look, act, and differentiate compared to normal cells (FIGO 1: well-differentiated cancer cells; FIGO 2: moderately differentiated; FIGO 3: poorly differentiated). Among those classified as uterine carcinomas, $60(53.6 \%)$ cases were found to have an FIGO 2. A total of $8(7.1 \%)$ specimens were not graded and considered high-grade cases (Table 1). 
Table 1 - Socio-demographic and clinical characteristics of the studied population.

\begin{tabular}{|c|c|}
\hline Variables & n (\%) \\
\hline Age, mean $\pm S D(\min -\max )$ & $54.40 \pm 16.1(1-91)$ \\
\hline Total & $200(100)$ \\
\hline \multicolumn{2}{|l|}{ Year } \\
\hline $\begin{array}{l}2015 \\
2016 \\
2017 \\
2018 \\
2019 \\
2020 \\
2021\end{array}$ & $\begin{array}{c}27(13.5) \\
35(17.5) \\
35(17.5) \\
21(10.5) \\
32(16.0) \\
31(15.5) \\
19(9.5)\end{array}$ \\
\hline \multicolumn{2}{|l|}{ Nationality } \\
\hline $\begin{array}{l}\text { Saudi } \\
\text { Non Saudi }\end{array}$ & $\begin{array}{c}168(84.0) \\
32(16.0)\end{array}$ \\
\hline \multicolumn{2}{|l|}{ Age } \\
\hline $\begin{array}{l}\geq 30 \text { years } \\
31-45 \text { years } \\
46-60 \text { years } \\
61-75 \text { years } \\
>75 \text { years }\end{array}$ & $\begin{array}{c}19(9.5) \\
31(15.5) \\
75(37.5) \\
60(30.0) \\
15(7.5)\end{array}$ \\
\hline \multicolumn{2}{|l|}{ Anatomical site } \\
\hline $\begin{array}{l}\text { Cervix } \\
\text { Ovary } \\
\text { Uterus } \\
\text { Vagina } \\
\text { Vulva }\end{array}$ & $\begin{array}{c}27(13.5) \\
27(13.5) \\
138(69.0) \\
3(1.5) \\
5(2.5)\end{array}$ \\
\hline \multicolumn{2}{|l|}{ Pathological grade } \\
\hline $\begin{array}{l}\text { FIGO grade1 } \\
\text { FIGO grade2 } \\
\text { FIGO grade3 } \\
\text { NA }\end{array}$ & $\begin{array}{c}33(29.5) \\
60(53.6) \\
11(9.8) \\
8(7.1)\end{array}$ \\
\hline \multicolumn{2}{|c|}{ Anatomical site of malignancy } \\
\hline $\begin{array}{l}\text { Cervix } \\
\text { Ovary } \\
\text { Uterus } \\
\text { Vagina } \\
\text { Vulva }\end{array}$ & $\begin{array}{c}27(13.5) \\
27(13.5) \\
138(69.0) \\
3(1.5) \\
5(2.5)\end{array}$ \\
\hline
\end{tabular}

SD: standard deviation, FIGO: Federation of Gynecology and Obstetrics NA: not applicable

The correlation of age and anatomical site of the malignancies was found to be significant overall using the Chi-square test $(p<0.001)$. For women aged 30 and below, the most common site of malignancies was the ovaries (57.9\%). Those aged from 31-75 years, all had the uterus as the most common anatomical site for the disease, as shown in Table 2. Additionally, no statistical difference was found between the ages of women with ovarian and vaginal malignancy $(p<0.001)$. The average ages for these 2 anatomical sites were found to be significantly different to those for cervical, uterine, and vulvar malignancies ( $p<0.001$; Table 2$)$.

The type of pathological diagnosis of malignancy was found to be significantly correlated to the variable of age overall. More specifically, it was established that tumors of the uterine corpus and uterine cervix were both significantly correlated to the mean age of women who were diagnosed at that site, with no significant differences between the 2 of them $(p>0.05)$. Additionally, one-way ANOVA and a least significant difference post hoc test determined that the mean ages of those diagnosed with uterine corpus and uterine cervix tumors are significantly different from the mean ages of those diagnosed with ovarian neoplasms, and gestational trophoblastic neoplasms $(p<0.001)$. Lastly, the mean age of patients with vulvar and vaginal tumors was statistically different from the mean age of patients who suffered from all the other pathological diagnoses $(p<0.001$; Table 3).

The cases of female genital malignancy were classified according to pathological diagnosis (Table 4). The majority were tumors of the uterine corpus (67.5\%), and the least common were gestational trophoblastic neoplasms (1.5\%). Tumors of the uterine corpus were further classified into epithelial, mesenchymal, or a mix of both, with more than three-quarters having epithelial origin tumors (86.7\%). Furthermore, endometrioid carcinoma (90.6\%) was found to be the prevalent type of epithelial tumor in the uterine corpus. On the other hand, low-grade endometrial stromal sarcoma (46.2\%) was the dominant type of mesenchymal tumor.

Ovarian neoplasms (13.5\%) were subdivided into 6 categories where most of the cases were found to be malignant epithelial tumors $(37.0 \%)$, specifically, serous carcinoma $(60.0 \%)$. Other subclasses of ovarian neoplasms include borderline epithelial tumors, sex cord tumors, germ cell tumors, plasmacytomas, and secondary tumors. For tumors of the uterine cervix (13.5\%), the dominant type of malignancy was squamous cell carcinoma $(88.9 \%)$. A similar result was obtained from vulvar and vaginal tumors with squamous cell carcinoma at $87.5 \%$. Finally, for gestational trophoblastic neoplasms, two-thirds $(66.6 \%)$ of the cases were choriocarcinomas, while only one $(33.3 \%)$ case was an epithelioid trophoblastic tumor (Table 4).

The prevalence of a specific type of pathological diagnosis was charted over 6 years (Figure 1). In total, tumors of the uterine corpus $(67.5 \%)$ predominantly accounted for more than $50 \%$ of cases in each year from 2015-2021 (Table 4). Gestational trophoblastic neoplasms accounted for less than $5 \%$ of yearly cases (Table 4). Similar cases number of vulvar and vaginal tumors were observed in the years 2017 (8.6\%) and 2019 (9.4\%) but decreased well into $2021(0.0 \%)$, as shown in Table 5. Ovarian neoplasms (20.0\%) and tumors of the uterine cervix (17.1\%) also revealed no significant increase in cases during 2017 compared from year 2015 and 2016. However, the former decreased to less than 
Table 2 - Correlation of age and anatomical site of the malignancies.

\begin{tabular}{|c|c|c|c|c|c|c|c|}
\hline \multirow[t]{2}{*}{ Variables } & \multirow[t]{2}{*}{ Total } & \multicolumn{6}{|c|}{ Age } \\
\hline & & $\geq 30$ years old ${ }^{*}$ & 31-45 years old ${ }^{*}$ & $\begin{array}{l}46-60 \text { years old } \\
\%)\end{array}$ & $61-75$ years old ${ }^{*}$ & $>75$ years old ${ }^{*}$ & Mean $\pm S D^{\dagger, \ddagger}$ \\
\hline Total & $200(100)$ & $19(100)$ & $31(100)$ & $75(100)$ & $60(100)$ & $15(100)$ & $54.40 \pm 16.1$ \\
\hline \multicolumn{8}{|c|}{ Anatomical site } \\
\hline $\begin{array}{l}\text { Cervix } \\
\text { Ovary } \\
\text { Uterus } \\
\text { Vagina } \\
\text { Vulva }\end{array}$ & $\begin{array}{c}27(13.5) \\
27(13.5) \\
138(69.0) \\
3(1.5) \\
5(2.5)\end{array}$ & $\begin{array}{c}1(5.3) \\
11(57.9) \\
5(26.3) \\
2(10.5) \\
0(0.0)\end{array}$ & $\begin{array}{c}7(22.6) \\
10(32.3) \\
13(41.9) \\
0(0.0) \\
1(3.2)\end{array}$ & $\begin{aligned} 11 & (14.7) \\
5 & (6.7) \\
58 & (77.3) \\
0 & (0.0) \\
1 & (1.3)\end{aligned}$ & $\begin{array}{c}5(8.3) \\
1(1.7) \\
50(83.3) \\
1(1.7) \\
3(5.0)\end{array}$ & $\begin{array}{c}3(20.0) \\
0(0.0) \\
12(80.0) \\
0(0.0) \\
0(0.0)\end{array}$ & $\begin{array}{l}54.67 \pm 13.9^{*} \\
34.89 \pm 15.5^{\dagger} \\
58.47 \pm 13.1^{*} \\
32.00 \pm 31.6^{\dagger} \\
59.40 \pm 12.3^{*}\end{array}$ \\
\hline
\end{tabular}

Table 3 - Pathological diagnosis of the patients.

\begin{tabular}{lc}
\hline Pathological diagnosis & $\mathbf{n}(\%)$ \\
\hline Tumours of uterine corpus & $135(67.5)$ \\
Epithelial tumours & $117(86.7)$ \\
Clear cell carcinoma & $3(2.6)$ \\
Endometrioid carcinoma & $106(90.6)$ \\
Serous carcinoma & $5(4.3)$ \\
Small cell neuroendocrine carcinoma & $1(0.9)$ \\
Undifferentiated carcinoma & $2(1.7)$ \\
Mesenchymal tumours & $13(9.6)$ \\
Endometrial stromal sarcoma, high-grade & $2(15.4)$ \\
Endometrial stromal sarcoma, low-grade & $6(46.2)$ \\
Leiomyosarcoma & $4(30.8)$ \\
Undifferentiated sarcoma & $1(7.7)$ \\
Mixed epithelial and mesenchymal tumours & $5(3.7)$ \\
Carcinosarcoma & $2(40.0)$ \\
Mixed cell carcinoma & $3(60.0)$ \\
Ovarian neoplasm & $27(13.5)$ \\
Epithelial tumours borderline & $6(22.2)$ \\
Mucinous borderline tumor with microinvasion & $2(33.3)$ \\
Serous borderline tumor & $2(33.3)$ \\
Serous borderline tumor, micropapillary variant & $2(33.3)$ \\
Epithelial tumours malignant & $10(37.0)$ \\
Endometrioid carcinoma & $1(10.0)$ \\
Mucinous adenocarcinoma & $3(30.0)$ \\
Serous carcinoma & $6(60.0)$ \\
Sex-cord tumours & $6(22.2)$ \\
Adult granulosa cell tumor & $5(83.3)$ \\
Juvenile granulosa tumour & $1(16.7)$ \\
Germ cell tumours & $3(11.1)$ \\
Dysgerminoma & $2(66.7)$ \\
Immature teratoma & $1(33.3)$ \\
Plasmacytoma & $1(3.7)$ \\
Plasmacytoma & $1(100)$ \\
Secondary tumours & $1(3.7)$ \\
Metastatic carcinoma & $1(100)$ \\
Tumour of uterine cervix & $27(13.5)$ \\
Clear cell carcinoma & $1(3.7)$ \\
Squamous cell carcinoma & $24(88.9)$ \\
Undifferentiated carcinoma & $2(7.4)$ \\
Valvar and vaginal tumours & $8(4.0)$ \\
Botryoid rhabdomyosarcoma & $1(12.5)$ \\
Squamous cell carcinoma & $7(87.5)$ \\
Gestational trophoblastic neoplasm & $3(1.5)$ \\
Choriocarcinoma & $1(33.3)$ \\
Epithelioid trophoblastic tumor & $1(33.3)$ \\
Gestational choriocarcinoma & $1(33.3)$ \\
\hline & \\
& \\
\hline
\end{tabular}

$5 \%(4.8 \%)$ in the following year (2018), whereas the tumors of the uterine cervix drastically decreased only in 2019 (3.1\%). No significant correlation was found in any of the variables and the trend of cases each year $(p>0.05$; Table 5).

Discussion. In Saudi Arabia, corpus uteri cancer is the fourth most prevalent type of cancer among Saudi women, only next to breast, thyroid, and colorectal cancers. Also, other female gynecological cancers were reported at much lower numbers. ${ }^{4}$ The incidence of these tumors varies greatly and is influenced by lifestyle choices, genetics, and socioeconomic status. ${ }^{7,8}$

A total of 200 cases of female genital malignancy from 2015-2021 were retrieved from $\mathrm{MCH}$. The mean age of the women was $54.40 \pm 16.1$ years. A 5-year retrospective study from Pakistan similarly reported the mean age range for most gynecological cancers as $51 \pm 12.7$ until $55 \pm 9.3$ years. ${ }^{8}$ Likewise, a study involving 443 Botswanan women also stated that the participants' mean age was $54.4 \pm 6.4$ years. ${ }^{9}$ A review on menopause and gynecological malignancy supported these results, stating that the probability of developing genital tractrelated cancers generally increased with the woman's age. ${ }^{10}$

The most common anatomical site for tumors was in the uterus $(69.0 \%)$, followed by the cervix (13.5\%), and the ovaries (13.5\%). This result differed from those found in a Nigerian study involving 166 gynecological malignancies. ${ }^{11}$ The research found cervical cancer $(59.6 \%)$ to be the most common among women, followed by ovarian malignancy (21.1\%). The large proportion was attributed to poor use and insufficient screening services on cervical cancer in Nigeria. ${ }^{11}$ Factors that affect this observation were ignorance, lack of knowledge on cervix-related disease prevention as well as initiative to seek health care. ${ }^{11-13}$ Corpus uteri cancer $(6.0 \%)$, on the other hand, was fourth in the number of incidences preceded by 
Table 4 - Female genital malignancies across different age groups.

\begin{tabular}{lcccccc}
\hline Variables & Total & 230 years old & 31-45 years old & $\begin{array}{c}\text { Age* } \\
\text { 46-60 years old } \\
\mathbf{n}(\%)\end{array}$ & 61-75 years old & $>75$ years old \\
\hline Total & $200(100)$ & $19(100)$ & $31(100)$ & $75(100)$ & $60(100)$ & $15(100)$ \\
Tumours of uterine corpus & $135(67.5)$ & $3(15.8)$ & $12(38.7)$ & $58(77.3)$ & $50(83.3)$ & $12(80.0)$ \\
Ovarian neoplasm & $27(13.5)$ & $11(57.9)$ & $10(32.3)$ & $5(6.7)$ & $1(1.7)$ & $0(0.0)$ \\
Tumour of uterine cervix & $27(13.5)$ & $1(5.3)$ & $7(22.6)$ & $11(14.7)$ & $5(8.3)$ & $3(20.0)$ \\
Valvar and vaginal tumours & $8(4.0)$ & $2(10.5)$ & $1(3.2)$ & $1(1.3)$ & $4(6.7)$ & $0(0.0)$ \\
Gestational trophoblastic neoplasm & $3(1.5)$ & $2(10.5)$ & $1(3.2)$ & $0(0.0)$ & $0(0.0)$ & $0(0.0)$ \\
\hline
\end{tabular}

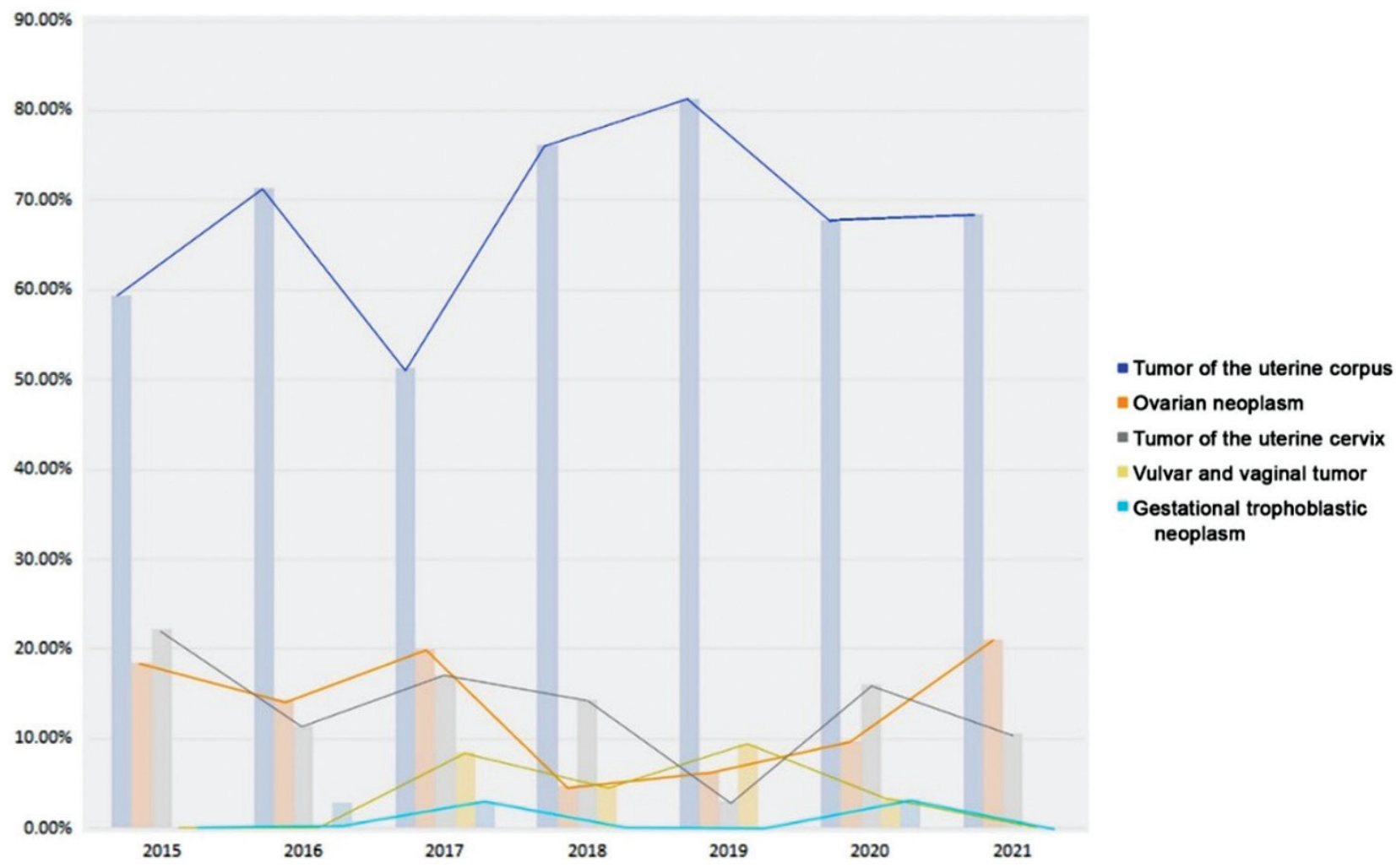

Figure 1 - The prevalence of a specific type of pathological diagnosis from 2015-2021.

Table 5 - Female genital malignancies across different years.

\begin{tabular}{lcccccccc}
\hline Variables & Total & \multicolumn{7}{c}{ Year } \\
& & 2015 & $\mathbf{2 0 1 6}$ & $\mathbf{2 0 1 7}$ & $\mathbf{2 0 1 8}$ & $\mathbf{2 0 1 9}$ & $\mathbf{2 0 2 0}$ & $\mathbf{2 0 2 1}$ \\
& & & \multicolumn{2}{c}{$\mathbf{n}(\%)$} \\
\hline Total & $200(100)$ & $27(100)$ & $35(100)$ & $35(100)$ & $21(100)$ & $32(100)$ & $31(100)$ & $19(100)$ \\
Tumours of uterine corpus & $135(67.5)$ & $16(59.3)$ & $25(71.4)$ & $18(51.4)$ & $16(76.2)$ & $26(81.3)$ & $21(67.7)$ & $13(68.4)$ \\
Ovarian neoplasm & $27(13.5)$ & $5(18.5)$ & $5(14.3)$ & $7(20.0)$ & $1(4.8)$ & $2(6.3)$ & $3(9.7)$ & $4(21.1)$ \\
Tumour of uterine cervix & $27(13.5)$ & $6(22.2)$ & $4(11.4)$ & $6(17.1)$ & $3(14.3)$ & $1(3.1)$ & $5(16.1)$ & $2(10.5)$ \\
Valvar and vaginal tumours & $8(4.0)$ & $0(0.0)$ & $0(0.0)$ & $3(8.6)$ & $1(4.8)$ & $3(9.4)$ & $1(3.2)$ & $0(0.0)$ \\
Gestational trophoblastic neoplasm & $3(1.5)$ & $0(0.0)$ & $1(2.9)$ & $1(2.9)$ & $0(0.0)$ & $0(0.0)$ & $1(3.2)$ & $0(0.0)$ \\
\hline
\end{tabular}


trophoblastic malignancy $(7.8 \%)$. It did support the finding that the vulva and vagina were the least common anatomical sites of tumors. ${ }^{11}$ A 12-year overview of gynecological malignancy in Pakistan involving 295 cases likewise reported ovarian (47\%) and cervical $(29 \%)$ tumors as the most common, placing uterine tumors third at $14 \%$ of incidences. ${ }^{7}$ In Korea, a 7 -year study found cervical cancer to be the most common, followed by uterine corpus malignancy. ${ }^{14}$

Cases of uterine carcinoma, the most commonly occurring tumor in this study, were classified according to the FIGO grading system. It was found that most of the uterine corpus carcinomas were classified as FIGO 2 (53.6\%). In New York, United States, FIGO 2 endometrial carcinoma was also the most common, accounting for $182(52.0 \%)$ cases, while FIGO 3 malignancy accounted for $25.0 \%$ of the cases and FIGO 1 accounted for the remaining 23.0\%. ${ }^{10}$ In contrast, Lee et $\mathrm{al}^{14}$ from South Korea reported that among 89 cases of uterine carcinoma, most were categorized as FIGO $1(83.7 \%)$ followed by FIGO 3 $(9.3 \%)$.

The age of women diagnosed with gynecological cancer was found to be significantly related to the anatomical site of the malignancy $(p<0.001)$. The mean age overall for the 200 cases was $54.40 \pm 16.1$ years. A similar report was made by Tanko et $\mathrm{al}^{9}$ with an average age of $54.50 \pm 6.40$ years among 400 women. A few studies have a lower age of presentation averaging $44.2 \pm 13$ years or a lower range of $40-59$ years for peak occurrence of genital malignancy. ${ }^{15,16}$

Interestingly, at ages 30 and below, tumors in the ovary and ovarian neoplasm were the most prominent type of malignancies. This result was contrary to the findings of Tanko et $\mathrm{al}^{9}$ and Kyari et $\mathrm{al}^{15}$ that both reported the range of 50-59 years as the range of the highest malignancy rates in the ovaries. A Nigerian study reported that the mean age of ovarian cancer occurrence was $51.5 \pm 14.7$ years. ${ }^{11}$ Manzoor et $\mathrm{al}^{7}$ also reported the age range 50-59 as the peak age of presentation for ovarian neoplasms. It should be noted, however, that the majority of the population were composed of women aged 46-60 years. In a study involving 25-year-old women in the United States, the most common malignancy was ovarian, comprising nearly half $(46.0 \%)$ of the cases. ${ }^{17}$

The mean age of occurrence of malignancy in the ovary was not significantly different from that of occurrence in the vagina. The mean ages of ovarian and vaginal incidences differed significantly from those of uterine, cervical, and vulvar incidences. Different studies reported varying peak age groups for the vagina as a site of occurrence of malignancy. A study from Batswana reported the mean age of vaginal malignancy at about 70 years of age, while another study reported that vaginal tumors are mostly found in the age group of 40-49 years. ${ }^{7,15}$ In terms of the type of malignancy, vulvar and vaginal tumors combined had a mean age of $49.13 \pm 23.9$ years, which remains insignificantly different from ovarian neoplasms. Contrary to the results of this study, a Nigerian research noted that the mean age of vaginal and vulvar cancer was about 70 years of age. ${ }^{11}$ Likewise, a Pakistani study revealed women above 60 years of age accounted for most of the vulva and vaginal cancers. ${ }^{7}$

Across all other age groups 30 years old and above (58.47 \pm 13.1 years old), malignancy in the uterus was the most dominant. Also, tumors of the uterine corpus were the predominant female gynecological malignancy across all studied age groups, having an average age of $59.08 \pm 12.5$ years old. Numerous studies have noted that uterine corpus malignancy in women primarily presents at 50 years of age. Kyari et $\mathrm{al}^{15}$ reported that the peak occurrence of tumors in the uterus was in the age group 50-59 years. However, Tanko et $\mathrm{al}^{9}$ had a peak occurrence at 70-79 years of age. In terms of the type of malignancy, Manzoor et $\mathrm{al}^{7}$ reported peak occurrence of uterine cancer in the age group 50-59 years, while Lee et $\mathrm{al}^{14}$ reported the average age for uterine corpus cancer to be 56.9 years. Other research also mentions the mean age for corpus uterine cancer to be $65.7 \pm 12.9$ years. ${ }^{11}$

The mean ages of patients with tumours of the uterine corpus and cervix were found to be significantly different from the mean age of occurrence of ovarian neoplasms, vulvar and vaginal tumors, and their respective anatomical sites. Some studies revealed 2 peak ages for cervical cancer incidence at 35 and 55 years old, while other studies stated that the age group of 40-49 years showed the highest occurrence of cervical malignancy, followed closely by the age group of 50-59 years. ${ }^{9,10,15}$ A retrospective study of 12 years reported that the dominant age group for cervical cancer was 40-49 years, followed closely by women aged 50-59 years. ${ }^{7}$ The study of Wasim et $\mathrm{al}^{8}$ reported a mean age of $43 \pm 8.98$ years for cervical cancer in 22 patients. Another study involving 115 clinically diagnosed uterine cervical cancer patients reported a mean age of 53.8 years, which agreed with the results of this research. ${ }^{14}$ Lastly, a study involving 166 women reported 99 of them having cervical cancer whose mean age was $54.0 \pm 10.6$ years old. ${ }^{11}$

This study explored the pattern of gynecological malignancies over 6 years (2015-2021). It was seen that over this period, tumors of the uterine corpus 
remained high and only decreased in incidences during the years 2017 and 2020. In the retrospective study of female gynecological cancers in China, there was an observed increase in the incidence of endometrial cancer, the most common type of uterine cancer. ${ }^{18}$ In South Africa, a 3-year study also concluded an increase in the occurrence of uterine cancer from 2006-2008, with only a slight decrease in the following year.' Interestingly, a 4-year study from 2009-2013 in Turkey, showed that tumors of the uterine corpus have the highest incidence of gynecological malignancy, which showed a steady increase in the first 2 years and a slow decline from 2011-2013. ${ }^{19}$ Malignancy in the vulva and vagina showed inconsistent changes in the number of incidences for the last 6 years, whereas gestational trophoblastic neoplasm incidences were low overall. In various studies, vulvovaginal malignancy was found to have low incidence rates, and this rate does not change drastically over time., ${ }^{9,19,20}$

The rate of ovarian neoplasm occurrence declined drastically from the year 2017-2018. However, the incidence gradually increased in the following years. A similar trend was seen in China, where rates of ovarian cancer gradually increased over 20 years starting from 1983. ${ }^{18}$ Tanko et $\mathrm{al}^{9}$ also illustrated a higher number of ovarian cancer diagnoses from 2006-2009. In contrast, a study from Turkey showed that ovarian cancer incidences from 2009-2013 generally decreased, except for an increase in 2011. ${ }^{19}$ In Estonia, the incidence of malignancy occurring in the ovary from 1999-2016 remained constant. ${ }^{18}$

This study found that there was a gradual decrease in cervical cancer incidences from 2015-2021 with an increase in the years 2017 and 2020. A South African study showed a different trend with a steady increase in cervical malignancy from 2006-2009. ${ }^{9}$ However, several studies noted that the rates of cervical cancer in Estonia, China, and Turkey remained unchanged over time. ${ }^{18-20}$

It was found that corpus uteri cancer was the most prevalent type of gynecological cancer from 2015-2021 at $3.6 \%$, followed by ovarian cancer at $1.6 \%$, cervix uteri cancer at $1.3 \%$, vulvar cancer at $0.05 \%$, and vaginal cancer at $0.01 \%$. In terms of cancer-related mortality, both corpus uteri and ovarian cancers had a mortality rate of $2.2 \%$, followed by cervix uteri cancer with $1.4 \%$, vulvar cancer with $0.04 \%$, and vaginal cancer with $0.02 \%$. Out of 100,000 people, approximately $25 \%$ may have corpus uteri cancer, approximately $9 \%$ may have ovarian cancer, and approximately $7 \%$ may have cervix uteri cancer. ${ }^{4}$

Findings of this study may provide future researchers to have a baseline references on gynecological malignancies in Al-Madinah Al-Munawarah, an important information in studying its trend for the succeeding years.

Study limitation. Associating gynecological malignancies against other sociodemographic factors (such as, society class/economic background) was not carried out to see the bigger picture of the cases and factors.

For further studies, it may be of interest to explore the economic background of the women being diagnosed, the type of their gynecological malignancy, and the frequency of diagnosis of particular social classes. A retrospective study in different areas in the region is also of interest for a better understanding of gynecological malignancy occurrence in a different demographic.

In conclusion, endometrial cancer was the most common malignancy $(69.0 \%)$ for women of 31 years and above. Overall, it was found that gynecological malignancy, specifically endometrial cancer, was common among female population in Al-Madinah Al-Munawarah region, having its presentation occurring at age range of 45-72 years old. This study showed that the most common anatomical site for gynecological malignancy was the uterus, with tumors of the uterine corpus having the highest incidence in the past 6 years. Most of the cancer incidences, regardless of pathological diagnosis, either increased or remained unchanged over time, a possible indication of the current state of health programs and information available to the citizens in Al-Madinah Al-Munawarah. Investigation that considers different social classes and demographic information may be of interest in understanding malignancy patterns and decreasing cancer burden.

Acknowledgment. The author gratefully acknowledge SCRIBENDI (https://www.scribendi.com) for English language editing.

\section{References}

1. Sung H, Ferlay J, Siegel RL, Laversanne M, Soerjomataram I, Jemal A, et al. Global cancer statistics 2020: GLOBOCAN estimates of incidence and mortality worldwide for 36 cancers in 185 countries. CA Cancer J Clin 2021; 71: 209-249.

2. Parkin DM, Pisani P, Ferlay J. Global cancer statistics. $C A$ Cancer J Clin 1999; 49: 33-64.

3. Sankaranarayanan R, Ferlay J. Worldwide burden of gynaecological cancer: the size of the problem. Best Pract Res Clin Obstet Gynaecol 2006; 20: 207-225.

4. World Health Organization - International Agency for Research on Cancer. Saudi Arabia: Globocan 2020. [Updated 2020; 2021 Nov 20]. Available from: https://gco.iarc.fr/today/data/ factsheets/populations/682-saudi-arabia-fact-sheets.pdf

5. Makoha FW, Raheem MA. Gynecological cancer incidence in a hospital population in Saudi Arabia: the effect of foreign immigration over two decades. J Obstet Gynaecol Res 2008; 34: 538-542. 
6. Pal S. Incidence of gynecologic cancers. US Pharm 2014; 39: 11.

7. Manzoor H, Naheed H, Ahmad K, Iftikhar S, Asif M, Shuja J, et al. Pattern of gynaecological malignancies in south western region of Pakistan: an overview of 12 years. Biomed Rep 2017; 7: 487-491.

8. Wasim T, Mushtaq J, Wasim AZ, Raana GE. Gynecological malignancies at tertiary care hospital, Pakistan: a five-year review. Pak J Med Sci 2021; 37: 621-627.

9. Tanko MN, Kayembe MA, Cainelli F, Vento S. Malignant tumours of the genital tract among Batswana women. Ghana Med J 2012; 46: 142-146.

10. Khatun S, Ferdous J. Menopause and gynecological malignancy. JSAFOMS 2013; 1: 75-79.

11. Ibrahim HM, Ijaiya MA. Pattern of gynaecological malignancies at the University of Ilorin Teaching Hospital, Ilorin, Nigeria. J Obstet Gynaecol 2013; 33: 194-196.

12. Chigbu CO, Aniebue U. Why southeastern Nigerian women who are aware of cervical cancer screening do not go for cervical cancer screening. Int J Gynecol Cancer 2011; 21: 1282-1286.

13. Nwankwo KC, Aniebue UU, Aguwa EN, Anarado AN, Agunwah E. Knowledge attitudes and practices of cervical cancer screening among urban and rural Nigerian women: a call for education and mass screening. Eur J Cancer Care (Engl) 2011; 20: 362-367.
14. Lee SY, Kim E, Kim HS, Koo YJ, Lee DH. Clinical and histopathologic analysis of gynecological cancer: a single institute experience over 7 years. Yeungnam Univ J Med 2020; 37: 179-185.

15. Kyari O, Nggada H, Mairiga A. Malignant tumours of female genital tract in North Eastern Nigeria. East Afr Med J 2004; 81: 142-145.

16. Thirukumar M, Sinnathurai A. Gynaecological malignancies among a representative population of Batticaloa, Sri Lanka. Cureus 2021; 13: e12947.

17. You W, Dainty LA, Rose GS, Krivak T, McHale MT, Olsen $\mathrm{CH}$, et al. Gynecologic malignancies in women aged less than 25 years. Obstet Gynecol 2005; 105: 1405-1409.

18. Kim K, Zang R, Choi SC, Ryu SY, Kim JW. Current status of gynecological cancer in China. J Gynecol Oncol 2009; 20: 72-76.

19. Gultekin M, Kucukyildiz I, Karaca MZ, Dundar S, Boztas G, Turan SH, et al. Trends of gynecological cancers in Turkey: Toward Europe or Asia? Int J Gynecol Cancer 2017; 27: 1525-1533.

20. Ojamaa K. Epidemiology of gynecological cancer in Estonia. University of Tartu 2019. 